gleiche harngefässe vorfand." It is perhaps worthy of note that this pentanephric condition obtains in Diptera which are by common consent among the most ancient and primitive of the order.

The foregoing remarks may be summarized as follows :-

I. It is very prohable that the socalled Malpighian vessels of Crustacea and Arachnida are not the homologues of the vasa Malpighi of the Eutracheata (Insects and Myriopods).

2. The Malpighian vessels of the Eutracheata arise as paired diverticula of the hind-gut and are, therefore, ectodermal.

3. In no insect embryo are more than 6 vessels known to occur; although frequently only 4 are developed.

4. The number 6 occurs either during embryonic or post-embryonic life in members of the following groups: Apterygota, Orthoptera, Corrodentia, Neuroptera, Panorpata, Trichoptera, Coleoptera, Lepidoptera and Hymenoptera.

5. The number 4 seems to be typical for the Corrodentia, Thysanoptera,
Aphaniptera, Rhynchota, Diptera and Hymenoptera.

6. The embryonic number in Dermaptera, Ephemeridea, Plecoptera and Odonata has not been ascertained, but will probably be found to be either 4 or 6 .

7. There is evidence that in at least one case (Melolontha) the tetranephric is ontogenetically derived from the hexanephric condition by the suppression of one pair of tubules.

8. It is probable that the insects which never develop more than 4 Malpighian vessels have lost a pair during their phylogeny.

9. The post-embryonic increase in the number of Malpighian vessels in some orders (Orthoptera, Odonata, Hymenoptera) is secondary and has apparently arisen to supply a demand for greater excreting surface.*

* There is a curious analogy between the excretory organs of these insects and the mesonephros of some vertebrates, where a second, third, etc., generation of tubules is added to the primitive metameric series. When the embryonic number of Malpighian vessels persists in insects, the demand for greater excreting surface is supplied by a lengthening of the individual vessels.

\title{
NOTE ON A SCUTELLERID ON NATIVE TOBACCO IN ARIZONA.
}

BY C. H. TYLER TOWNSEND, KINGSTON, JAMAICA.

At Cedar Ranch, Arizona, which is the half-way station on the stage route from Flagstaff to the Grand Cañon, I found on July $6, \mathrm{r} 892$, a scutellerid in numbers on a species of native tobacco, Nicotiana sp. probably attenuata. This locality is also called Hull Spring, and is on the edge of the somewhat mountainous country which lies to the south of it, a more or less level plateau extending to the north between it and the cañon. The native tobacco upon which the insects were found grew in patches about the spring, which is 
located a few hundred yards to the south at the base of the north slope of the wooded hills. The scutellerid was very numerous on the Nicotiana, and lives on the juices of the plant. About thirty adults were taken, but only one larva. This was the only larva seen at this date, but hundreds of the adults could have been collected. Some ants were observed, which appeared to linger about the scutellerids.

Specimens of the latter were sent to Mr. Uhler and Dr. Riley, and determined by them as Corimelaena extensa Uhi. This record is of interest as noting a scutellerid which affects Nicotiana. I know of no previous mention of a member of this family of insects living upon this plant.

The adult of $C$. extensa is shining black, with the hemelytra widely, almost wholly creamy on the sides. The larva is very similarly colored, being also black with a patch of creamy on the sides of body, the hemelytra being not yet developed. It may be more definitely described as follows:

Larva of Corimelaena extensa.- Length, $\mathrm{I}_{2} \frac{1}{2} \mathrm{~mm}$.; width, I $\mathrm{mm}$. Body clothed somewhat sparsely with short pubescence. Head triangular in outline from above, narrower than thorax, shining black above and below, the usually invisible membranous neck-like portion which attaches the head to the thorax being pale or light colored. Eyes brownish.
Antennae pale-colored, pubescent, 4-jointed, last joint longest and stoutest, three basal joints nearly same length and size. Beak elongate, reaching beneath body as far back as origin of hind pair of legs, pale colored, 3-jointed, basal joint a little the longest, last two joints nearly the same length, the second joint a little stouter than the last. Thorax about one-third broader than head, shining black above and below. Legs pale colored, except femora which are mostly darker. Abdomen as wide as thorax, rounded behind, vaulted and convex, cistudinate (in the dried specimen), exposed and bare, widely shining black on the median portion longitudinally, narrowly so on the lateral edges, between the two with a lateral longitudinal stripe of creamy whitish which gradually narrows to a point posteriorly. Ventral surface of abdomen very concave, and showing same coloring. Scutellum and wings wholly undeveloped.

One specimen, July 6 , on Nicotiana. Arizona.

In the adult the last joint of antennae is no longer nor larger than the preceding two joints, to each of which it is nearly equal. The legs are almost wholly blackish or brownish, except the tarsi and tips of tibiae. The beak is brownish and 3-jointed, antennae pale. Whole upper surface of head, thorax and scutellum is dark metallic green. Wing covers are extremely narrow, creamy except a narrow dark green line on inner edge which broadens at base.
A New Entomological Journal. - The New York entomological society began early this year the publication of a quarterly journal, of which three parts have already appeared, extending to nearly I5O pages.
Most of the articles, as is fitting, bear particular reference to the insects of the neighboring region, and render the journal of special value in this respect; besides which are not a few papers of permanent interest. 

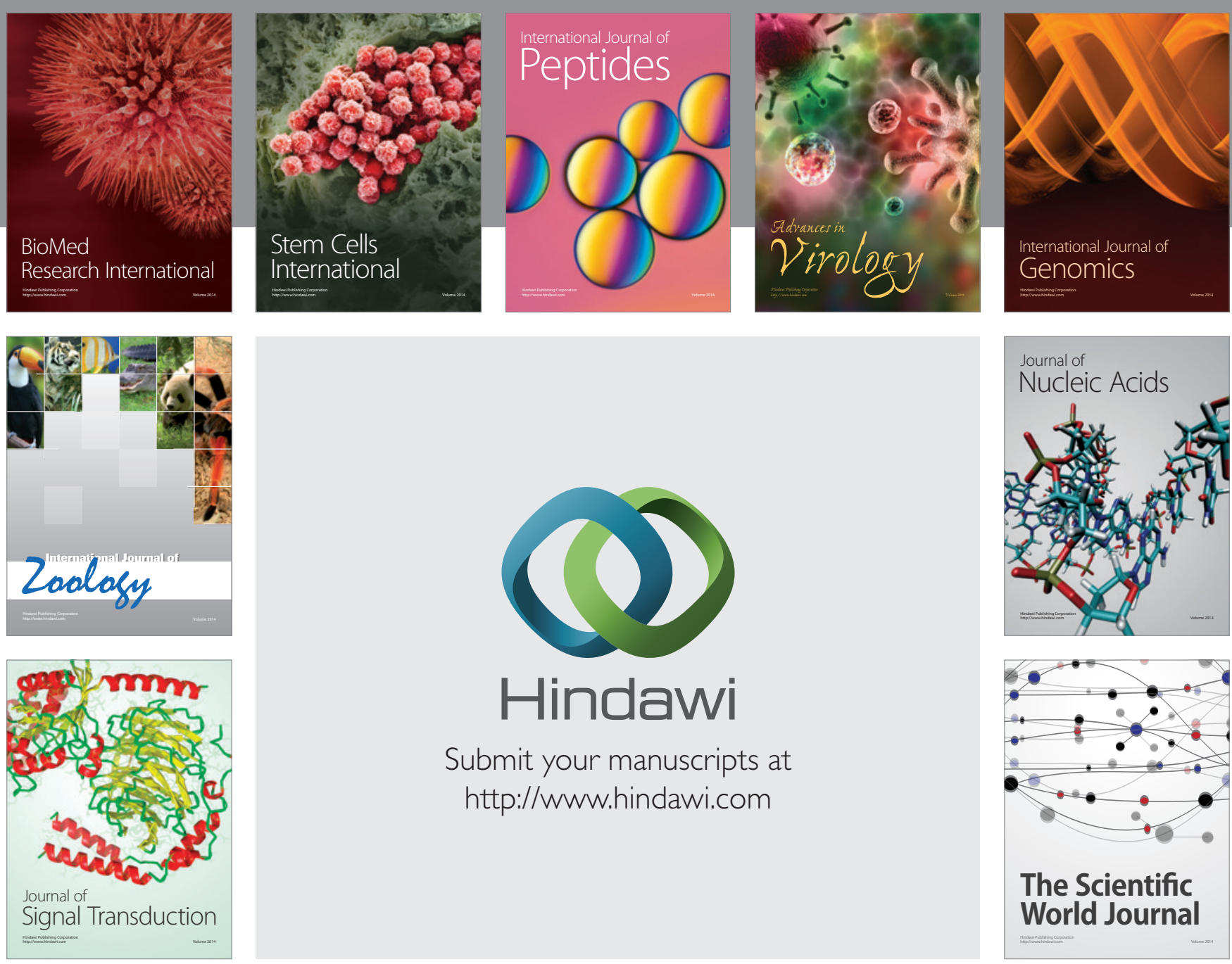

Submit your manuscripts at

http://www.hindawi.com
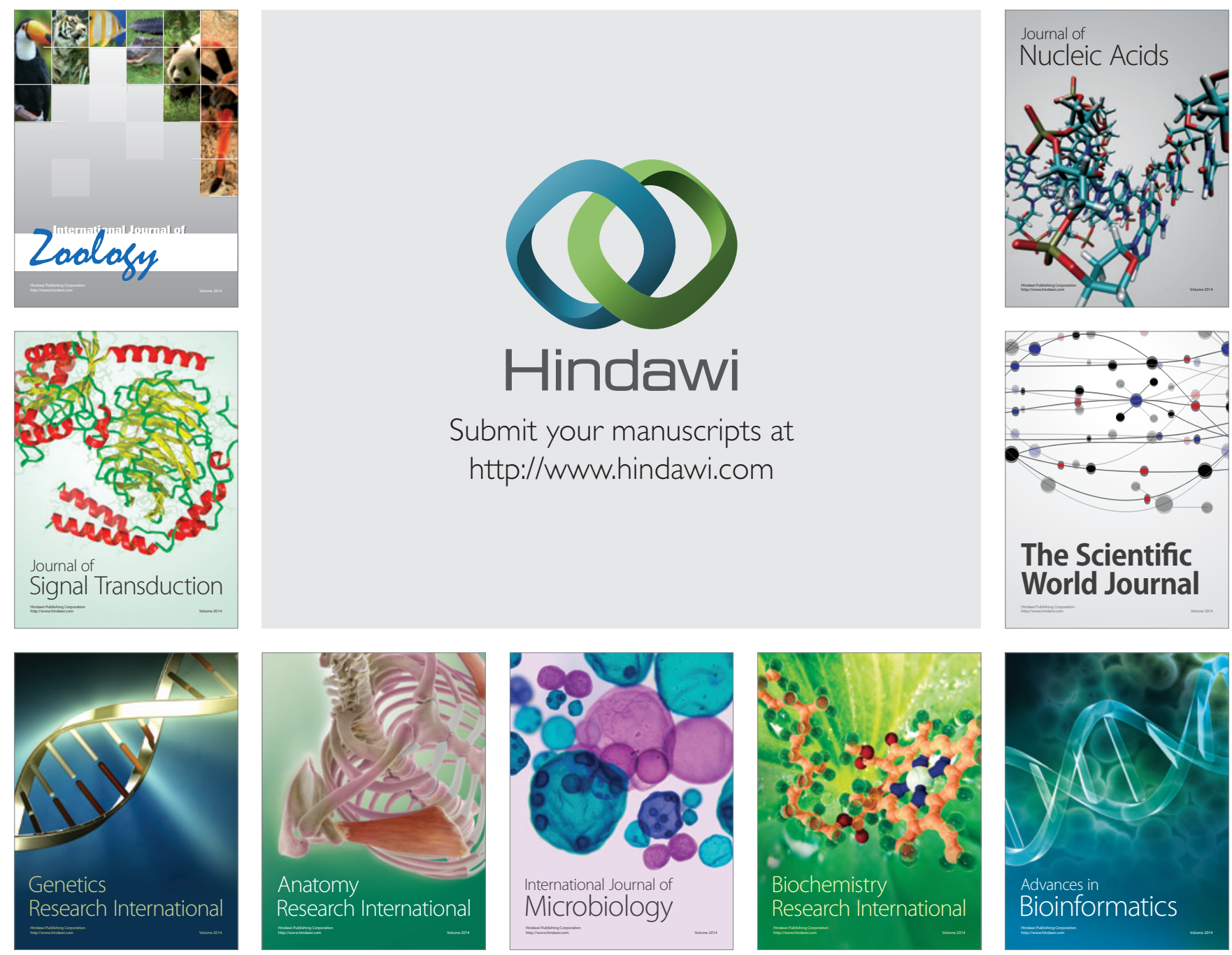

The Scientific World Journal
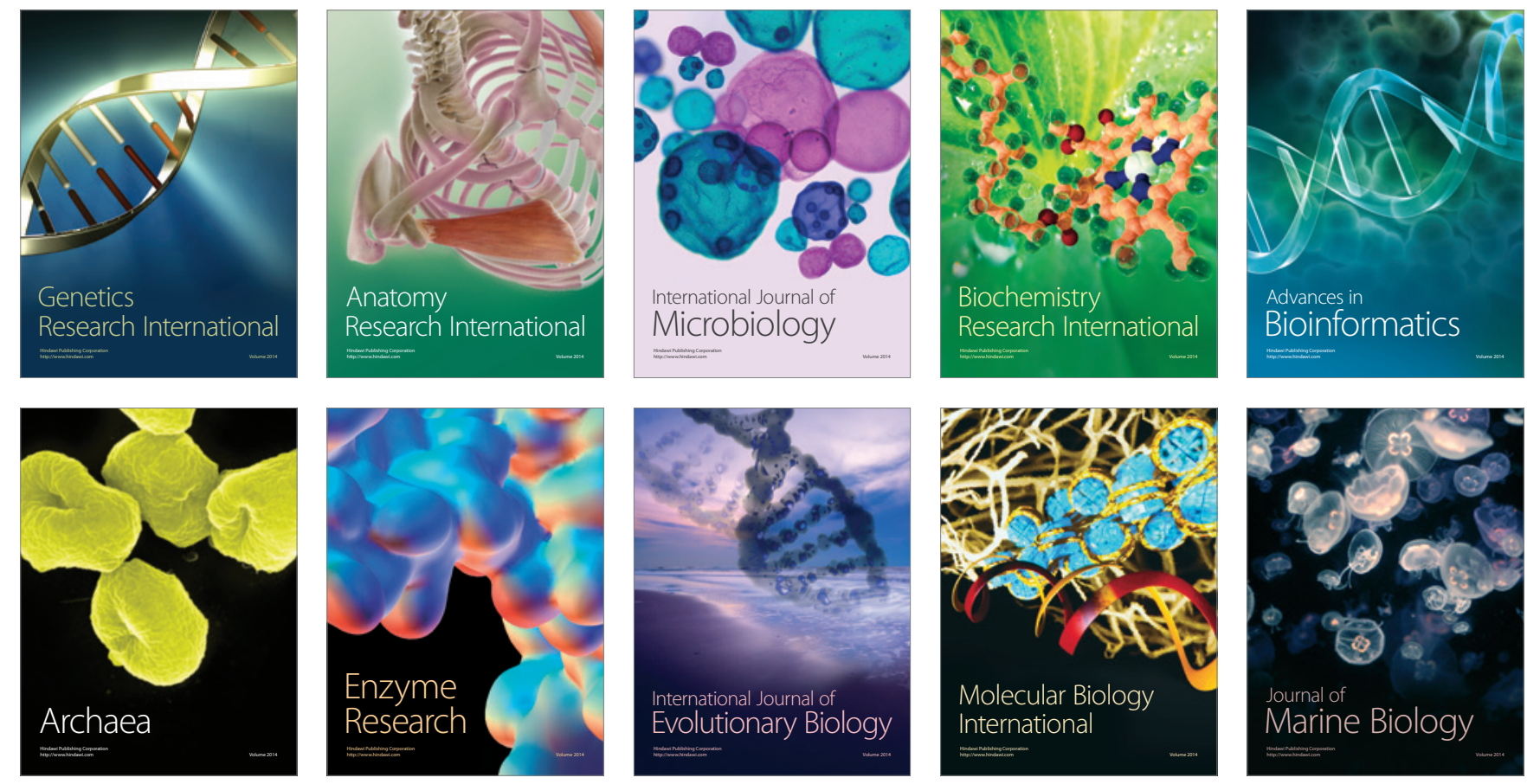